\title{
Azathioprine-induced accelerated cutaneous and pulmonary nodulosis in a patient with rheumatoid arthritis*
}

\author{
Cristian Vera Kellet ${ }^{1}$ \\ Sergio González Bombardieri ${ }^{1}$
}

\author{
Romina Andino Navarrete ${ }^{1}$ \\ Juan Manriquez ${ }^{1}$
}

DOI: http:/ / dx.doi.org/10.1590/abd1806-4841.20153750

\begin{abstract}
A bstract: We report the case of a 42-year-old female with a 5-year history of rheumatoid arthritis treated with Rituximab and Azathioprine. Three months after the initiation of Azathioprine, the patient started with dry cough and noted the rapid development of multiple subcutaneous nodules on her right leg. CT scan of the chest demonstrates pulmonary nodulosis. Skin biopsy was compatible with rheumatoid nodule. A diagnosis of "accelerated cutaneous and pulmonary nodulosis" was considered. Azathioprine was discontinued and Rituximab was restarted. Two months later, most of the subcutaneous nodules had disappeared. This is the second case report of accelerated rheumatoid nodulosis in association with Azathioprine treatment.
\end{abstract}

Keywords: Arthritis, rheumatoid; Azathioprine; Rheumatoid nodule

\section{INIRODUCTION}

Rheumatoid arthritis (RA) is an immune-mediated disease involving chronic inflammation and joint destruction. The skin is the most common extra-articular target of RA. ${ }^{1}$ Subcutaneous nodules are common and occur as classic rheumatoid nodules, accelerated rheumatoid nodulosis, mainly by methotrexate (MTX), or rheumatoid nodulosis. ${ }^{2}$ Accelerated rheumatoid nodulosis has been reported only once in association with azathioprine therapy. ${ }^{3}$

We report the case of a patient with RA treated with azathioprine who subsequently developed accelerated cutaneous and pulmonary nodulosis.

\section{CASE REPORT}

A 42-year-old-female with a 5-year history of arthritis of the fingers, swollen hand joints and positive testing for rheumatoid factor. Nodules on the hands and other parts of the body were not observed. She was treated with different disease-modifying antirrheumatic drugs (initially MTX was given, then infliximab, and both were accompanied by at least $5 \mathrm{mg}$ of prednisone daily) with limited efficacy and development of episcleritis. Treatment with rituximab and azathioprine was started in 2011 with complete clinical response.

Three months after the initiation of azathioprine, with RA in remission, the patient started with cough without other respiratory symptoms and noted the rapid development of multiple small subcutaneous nodules on her right leg (Figure 1).

The patient was a non-smoker and routine pre-treatment screening involved a chest radiograph (normal) and a PPD test (negative). CT scan of the chest demonstrates pulmonary nodulosis (Figure 2). QuantiFERON ${ }^{\circledR}$-TB was conclusively negative.

A diagnosis of "accelerated cutaneous and pulmonary nodulosis" was considered. Biopsy of the subcutaneous nodule revealed a necrotizing area surrounded by a palisade of histiocytes and chronic inflammatory cells compatible with rheumatoid nodule (Figures 3 and 4). 
Azathioprine was discontinued and Rituximab was restarted. Two months later, most of the subcutaneous nodules had disappeared.

\section{DISASSION}

Accelerated rheumatoid nodulosis was first noted in 1986 by Kremer and Lee during a study of long term MTX therapy for RA. ${ }^{2}$ Since then, others have observed the same phenomenon in $8 \%-11 \%$ of MTX-treated RA patients. ${ }^{1}$

This condition may develop despite improvement of arthritic symptoms and it regresses when methotrexate is reduced or withdrawn ${ }^{1}$. The mean time period from commencement of MTX therapy to the onset of subcutaneous nodulosis is nearly 3 years. ${ }^{4}$ HLA-DRB1*0401 and rheumatoid factor seropositivity have been associated with MTX-induced nodulosis. ${ }^{2}$

Accelerated rheumatoid nodulosis has also been reported in patients treated with etanercept and leflunomide and only once in association with azathioprine treatment. ${ }^{1,3}$

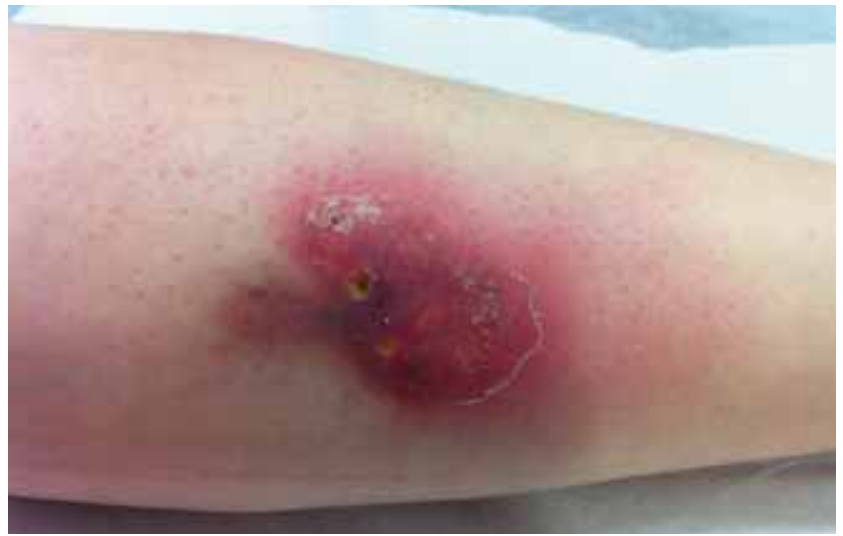

Figure 1: Multiple subcutaneous nodules on the right leg of a patient after treatment with Azathioprine

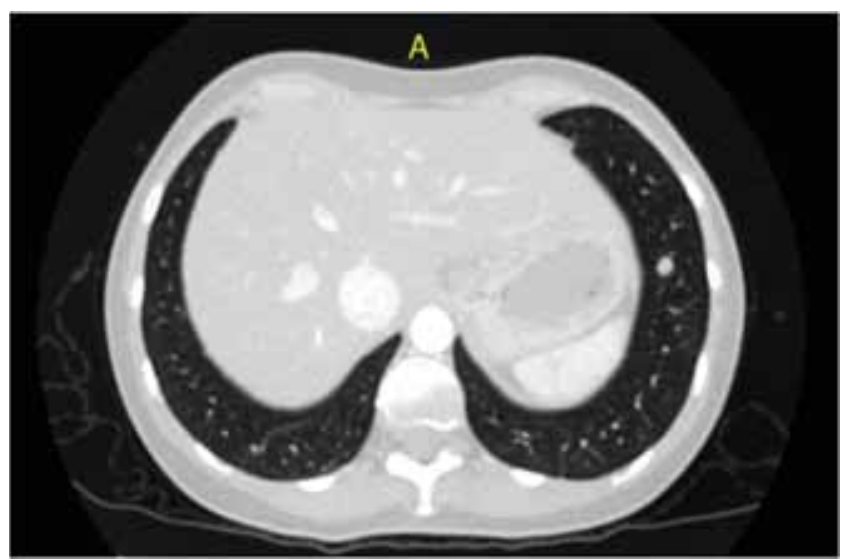

FIgURE 2: High-resolution CT image through the lower lung zone demonstrates peripheral nodule

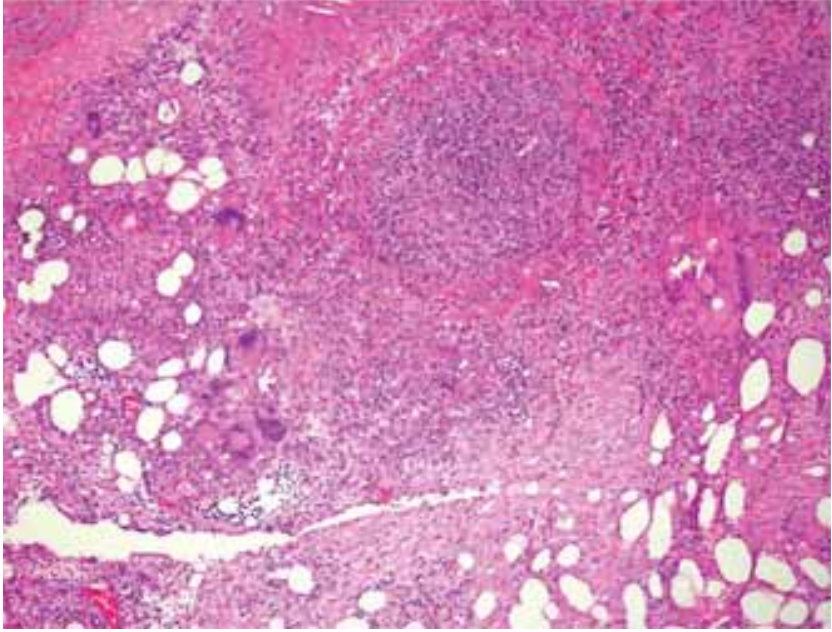

FIgURE 3: Microphotograph showing a rheumatoid granuloma with fibrinoid necrosis surrounded by lymphocytes and epithelioid cells in a palisade arrangement, and vasculitis of a hypodermic vein (HE: 200X)

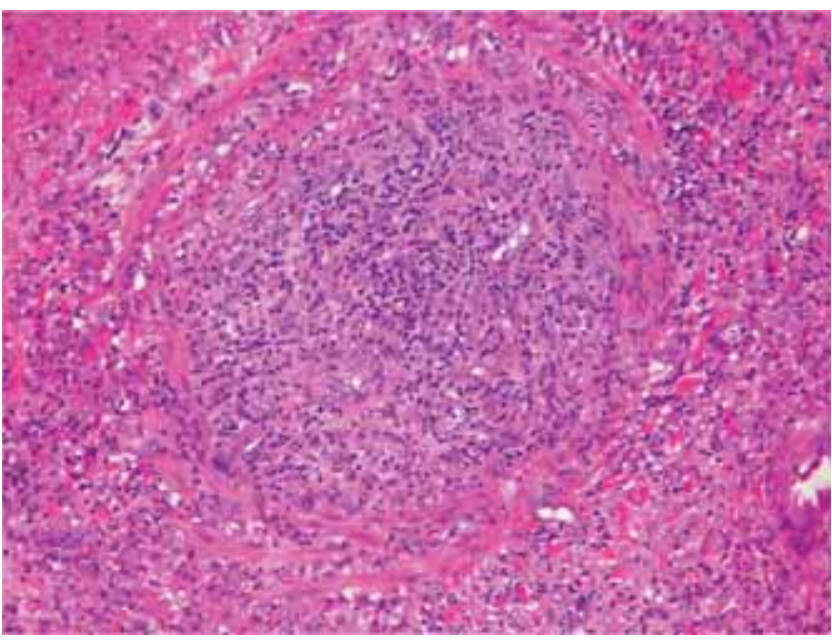

FIgURE 4: Microphotograph showing a rheumatoid granuloma with fibrinoid necrosis surrounded by lymphocytes and epithelioid cells in a palisade arrangement, and vasculitis of a hypodermic vein (HE: 400X)

The nodules affect mainly the hands (metacarpophalangeal and proximal interphalangeal joints) and other areas prone to chronic repetitive irritation, although they can occur in a variety of sites, including the larynx, heart, lungs, sclera, tendons, synovium, bones, peritoneum, central nervous system, and vertebral bodies. ${ }^{2,5}$

Clinically, they are subcutaneous skin-colored nodules and vary in consistency from a firm rubbery texture to an amorphous and mobile mass. They range in size from millimeters to several centimeters. ${ }^{5}$ 
The nodules are histologically identical to nonMTX-induced rheumatoid nodules. They have three zones: an inner central necrotic zone, a second zone composed of palisading macrophages and an outer layer of perivascular granulation tissue with chronic inflammatory cells. ${ }^{2,6}$

The pathogenesis of accelerated nodulosis is still unknown, although one study identified an adenosine-a1-receptor-mediated pathway involved in MTX-induced nodulosis. This manifestation has never been observed in cancer patients treated with methotrexate, suggesting that the pathogenetic mechanisms of RA are of special importance. ${ }^{1}$ A recent publication reports a case of MTX-induced accelerated rheumatoid nodulosis with MTX-associated lymphoproliferative disorder (LPD) where Epstein-Barr virus (EBV) was detected in rheumatoid nodules and lymph nodes.
The authors propose that the improvement with the cessation of MTX suggests that MTX-associated immunosuppression can impair immune surveillance of EBV-infected cells; leading to the development of EBV-associated MTX-induced accelerated rheumatoid nodulosis, as well as MTX-LPD. ${ }^{7}$

There is no effective treatment for accelerated rheumatoid nodulosis. The principal option is discontinuance of the causal drug. In our patient, azathioprine suspension and Rituximab restart was effective. ${ }^{1,6}$

We report the case of a patient with RA treated with azathioprine, who subsequently developed accelerated cutaneous and pulmonary nodulosis. Early diagnosis and rapid discontinuation of the drug were critical for the successful evolution of this case.]

\section{REFERENCES}

1. Prete M, Racanelli V, Digiglio L, Vacca A, Dammacco F, Perosa F. Extra-articular manifestations of rheumatoid arthritis: An update. Autoimmun Rev. 2011;11: 123-31.

2. Sayah A, English JC 3rd. Rheumatoid arthritis: a review of the cutaneous manifestations. J Am Acad Dermatol. 2005;53:191-209.

3. Langevitz P, Maguire L, Urowitz M. Accelerated nodulosis during azathioprine therapy. Arthritis Rheum. 1991;34:123-4.

4. Yamamoto T. Cutaneous manifestations associated with rheumatoid arthritis. Rheumatol Int. 2009;29:979-88.

5. Hata T, Kavanaugh A. Rheumatoid arthritis in dermatology. Clin Dermatol. 2006;24:430-7.

6. Motegi S, Ishikawa 0. Methotrexate-induced Accelerated Nodulosis in a Patient with Rheumatoid Arthritis and Scleroderma. Acta Derm Venereol. 2014;94:357-8.

7. Shimoura N, Fukunaga A, Nagai H, Oka M, Nishigori C. Epstein-Barr Virusassociated Methotrexate-induced Accelerated Rheumatoid Nodulosis. Acta Derm Venereol. 2015;95:100-1.
M AILING ADDRESS:

Juan $M$ anriquez

4686 V icuña M ackenna St. Santiago

Chile

E-mail: jjmanriq@gmail.com

How to cite this article: Vera-Kellet C, Andino-Navarrete R, Gonzalez S, Manriquez J. Azathioprine-induced accelerated cutaneous and pulmonary nodulosis in a patient with rheumatoid arthritis. An Bras Dermatol. 2015;90 (3 Suppl 1):162-4. 